\title{
BMJ Open Effect of birth order on stereoacuity in Chinese preschool children: a cross- sectional study
}

\author{
Shu Han, ${ }^{1}$ Xiaohan Zhang, ${ }^{2}$ Rui Li, ${ }^{3}$ Haohai Tong, ${ }^{3}$ Xiaoyan Zhao, ${ }^{3}$ Yue Wang, ${ }^{3}$ \\ Qingfeng Hao, ${ }^{3}$ Dan Huang, ${ }^{3}$ Hui Zhu, ${ }^{3}$ Xiaojun Zhang, ${ }^{1}$ Hu Liu (i) ${ }^{3}$
}

To cite: Han S, Zhang X, Li R, et al. Effect of birth order on stereoacuity in Chinese preschool children: a crosssectional study. BMJ Open 2020;10:e032833. doi:10.1136/ bmjopen-2019-032833

- Prepublication history for this paper is available online. To view these files, please visit the journal online (http://dx.doi. org/10.1136/bmjopen-2019032833).

SH and XHZ contributed equally.

Received 09 July 2019

Revised 07 July 2020

Accepted 04 August 2020

D Check for updates

(C) Author(s) (or their employer(s)) 2020. Re-use permitted under CC BY-NC. No commercial re-use. See rights and permissions. Published by BMJ.

${ }^{1}$ Ophthalmology, The Second Affiliated Hospital of Nanjing Medical University, Nanjing,

China

${ }^{2}$ Ophthalmology, The Affiliated Wuxi Children's Hospital of Nanjing Medical University, Wuxi, China

${ }^{3}$ Ophthalmology, The First Affiliated Hospital of Nanjing Medical University, Nanjing, China

Correspondence to Dr Hu Liu; liuhu@njmu.edu.cn

\section{ABSTRACT}

Objective This study aimed to investigate the relationship between birth order and stereoacuity among Chinese children aged 60-72 months.

Design Cross-sectional.

Participants 1342 children with complete data on the questionnaire, stereoacuity and refraction were included. Results The mean stereoacuity was $53.2 \pm 1.7,56.9 \pm 1.9$ and $60.9 \pm 1.5 \mathrm{~s}$ of arc in the first-born group, second-born group and third-born group, respectively. Lower birth order was significantly correlated with better stereoacuity $(p=0.036)$. Third-borns $(0 R=3.02, p=0.027)$ were at higher risk of having subnormal stereoacuity compared with firstborns in the multivariate analysis.

Conclusion Later-borns had poorer stereoacuity than first-borns.

\section{INTRODUCTION}

Due to the Chinese two-child policy, we are caught on the horns of a dilemma of an increasing demand for paediatric vision care and a decreasing professional care due to second-child maternity leave. ${ }^{1}$ To the best of our knowledge, studies on Chinese laterborns are insufficient, and there is dire need to identify these Chinese later-borns.

Birth order could predict intelligence, personality and behaviours, according to extensive research conducted around the world..$^{2-4}$ In particular, several studies have reported that higher birth order was associated with higher risk of neurodevelopmental disorders. ${ }^{5}{ }^{6}$ As an important part of early neurological development, a reduced level of stereoacuity has a negative impact on the ability of an individual to perform many tasks, thus leading to bad interactions with the world.

As we all know, stereoacuity is the highest fusion sensory of binocular vision and has impact on the performance of fine visual and motor action. Children with poor stereoacuity might have serious visual developmental disorder, which could lead to reading difficulties in kindergarten and to poor intelligence

\section{Strengths and limitations of this study}

To our limited knowledge, no report has demonstrated the correlation between birth order and stereoacuity.

With the two-child policy in China, evaluating the effects of this baby boom on stereoacuity might benefit both families and the society.

- This is a population-based study comprising 1342 children aged 60-72 months.

- This study provided data, such as mean stereoacuity, which could be valuable to primary eye care in China.

- Some children without examinations were excluded which might bias the results, and some inaccurate stereoacuities might exist due to limited compliance.

in first-grade children. ${ }^{78}$ However, to our limited knowledge, there is a serious lack of study on whether birth order is correlated with stereoacuity in Chinese preschool children. In addition, it has been estimated that 90 million Chinese couples could have a second child following the two-child policy in China. ${ }^{1}$ Thus, assessing the relationship between birth order and stereoacuity has certain value in China nowadays.

This study is part of the Nanjing Eye Study (NES) and was designed to investigate the association between birth order and stereoacuity in Chinese preschool children and to provide some insights into paediatric care, and is timely with the increasing burden on primary care in China.

\section{MATERIALS AND METHODS}

This cross-sectional study is part of NES, a population-based cohort study designed to longitudinally assess the onset and progression of paediatric ocular diseases in Eastern China. ${ }^{9-12}$ As described previously, ${ }^{9}{ }^{12}$ all children born between September 2011 and August 2012 and resided in Yuhuatai District, Nanjing, China were invited to participate 
in NES to undergo comprehensive eye examinations. In 2017 , efforts to disseminate the benefits of our study to the legal guardians of these preschool children led to a participation rate of $83.5 \%$ (1920 of 2300). The data analysed for this study were obtained in 2017, when these children were 60-72 months old.

Written informed consent was obtained from the parents or legal guardians of all participants. Oral assent was obtained from all children right before the examination.

\section{Ocular examinations}

A comprehensive eye examination of participants was performed by a team composed of six trained ophthalmologists and four optometrists. Children roster and basic information including name, gender and birth date were all obtained from each kindergarten's principal and the information was then verified. Measurements included anthropometric parameters, distance visual acuity (VA), anterior segment and fundus examination, refraction before and after cycloplegia, Randot Preschool Stereoacuity Test, ocular alignment and motility, ocular biometric parameters, intraocular pressure, accommodative response, and optical coherence tomography. Children with suspected or confirmed eye problems were referred to senior ophthalmologists and underwent further examinations.

Distance VA was measured with a retroilluminated (ESV1200 Illuminated Cabinet, Good-Lite, Perth Amboy, New Jersey, USA) linear HOTV logMAR (logarithm of the minimum angle of resolution) chart (600 017, GoodLite) at a distance of $3 \mathrm{~m}$, right eye followed by left eye, as described before. ${ }^{10}{ }^{12}$ Additionally, children who wore spectacles were measured both with and without spectacles. Best corrected VA was recorded with full correction under cycloplegia.

Refractive status of each participant was measured before cycloplegia using table-mounted autorefraction (Canon R-F10, Tokyo, Japan) and photorefraction (PlusoptiX, Nuremberg, Germany). Cycloplegic refraction was performed after cycloplegia using table-mounted autorefraction and retinoscopy. One drop of topical 1.0\% cyclopentolate eye-drop (Cyclogyl, Alcon Pharmaceuticals, Belgium) was administered to each eye twice at $5 \mathrm{~min}$ intervals. Fifteen minutes later, a third drop was administered if the pupil size was $<6 \mathrm{~mm}$ or if the pupillary light reflex was still present.

Before cycloplegia, stereopsis thresholds were measured with the Randot Preschool Stereoacuity Test (Stereo Optical, Chicago, Illinois, USA) at a distance of $40 \mathrm{~cm}$, following standardised testing procedure. Disparities in the Randot Preschool Stereoacuity Test ranged from 800 to $40 \mathrm{~s}$ of arc in unequal step sizes. Subjects viewed the stereogram through a pair of polarised glasses. Spectacles, if provided, were also worn. At each disparity level, the subject must correctly identify at least two of the three test shapes. Stereoacuity tests were labelled test 1 , test 2 and test 3 , respectively. The child was first asked to point out the shapes on the left page of the booklet or to name each shape seen in test 1 . If the child could respond correctly to the $200 \mathrm{~s}$ of arc test object (top of test 1 ), the child was encouraged to proceed to the $100 \mathrm{~s}$ of arc test object (bottom of test 1 ). If the child passed test 1 , testing proceeded to test 2 at 60 and $40 \mathrm{~s}$ of arc level, as described in test 1 . If correct responses were not obtained at the $200 \mathrm{~s}$ of arc level, the child proceeded to test 3 at 800 and $400 \mathrm{~s}$ of arc level. If the child was unable to consistently identify most of the two-dimensional shapes on the left-hand pages, the subject was scored with 'unable' stereoacuity. Otherwise the smallest disparity at which the child was able to identify two of the three test shapes was recorded as the final stereoacuity.

\section{Questionnaire}

A comprehensive questionnaire composed of six parts was distributed to the legal guardian of each participant. Detailed data concerning basic information of the children and their parents, history of pregnancy, birth and feeding, daily activities, sleep quality of children, home environment, and guardian's concerns over the eyes of each child were all collected. Maternal age, gestational age at birth (weeks), birth weight, Apgar score at $5 \mathrm{~min}$, delivery mode, neonatal oxygen supplementation, birth order, smoking exposure, breast feeding and so on were collected in the history of pregnancy, birth and feeding sections of the questionnaire.

\section{Definitions}

Spherical equivalent (SE) was calculated as spherical dioptre (D) plus half of the dioptre of cylindrical power. Myopia was defined as SE $\leq-0.50 \mathrm{D}$ in either eye, hyperopia defined as $\mathrm{SE} \geq+2.00 \mathrm{D}$ in either eye, astigmatism defined as cylindrical power $\geq 1.00 \mathrm{D}$ in either eye, and anisometropia was defined as SE difference $\geq 1.00 \mathrm{D}$ between the two eyes. Strabismus was defined if any tropia was present at a distance or near, with or without spectacles. Amblyopia was defined similar to the Multiethnic Pediatric Eye Disease Study. ${ }^{13}$ Subnormal stereoacuity was defined as stereoacuity worse than $40 \mathrm{~s}$ of arc (stereoacuity value $>40 \mathrm{~s}$ of arc). ${ }^{14}$

\section{Statistical analyses}

Stereoacuity scores in seconds of arc were first transformed into a logarithmic value before statistical modelling, and the results in log units were transformed back to the original value after statistical analysis for easy clinical interpretation of results. Children unable to perform stereoacuity test were assigned $2000 \mathrm{~s}$ of arc for statistical analyses.

A t-test was used to compare the means for continuous variables and $\chi^{2}$ test to compare percentages between groups. Mean test was performed to find the difference in stereoacuity between birth order groups. Univariate and multivariable linear regression analyses were performed to evaluate the association of factors with stereoacuity scores, including gender, age in months, gestational 
age at birth (weeks), birth weight, Apgar score at 5 min, delivery mode, neonatal oxygen supplementation, birth order, smoking exposure and breast feeding. Only factors with $\mathrm{p}<0.10$ in univariate regression analysis were retained in multivariable regression model. Similarly, binary logistic regression models were fitted to determine the factors associated with subnormal stereoacuity. All statistical tests were performed using the Statistical Package for the Social Sciences (SPSS) V.13.0 statistical software, and $p<0.05$ was considered statistically significant. As to refraction, cycloplegic refraction was used if available and non-cycloplegic refraction was used only if cycloplegic refraction data were not available.

\section{Patient and public involvement}

Patients and the public were not involved in any aspects of the study, including the development of study question, study design, conduct of the study and dissemination of results.

\section{RESULTS}

\section{Study population}

Among the participants, 1342 (69.9\%) preschool children with complete data on the comprehensive questionnaire, stereoacuity and refraction were included in the analyses. There were 721 (53.7\%) boys and 621 (46.3\%) girls, with a mean \pm SD age of $66.71 \pm 3.32$ months for boys and $66.88 \pm 3.44$ months for girls $(\mathrm{p}=0.36)$. Table 1 shows the characteristics of early life factors among preschool children in the NES.

\section{Distribution of stereoacuity in preschool children}

Table 2 and figure 1 show the distribution of stereoacuity in preschool children overall and by birth order groups. The mean $\pm \mathrm{SD}$ of stereoacuity was $54.0 \pm 1.7 \mathrm{~s}$ of arc among preschool children, $54.8 \pm 1.8 \mathrm{~s}$ of arc for boys and $53.1 \pm 1.7 \mathrm{~s}$ of arc for girls $(\mathrm{p}=0.31)$. Children with $40 \mathrm{~s}$ of arc accounted for the largest percentage $(55.1 \%)$, followed by $60 \mathrm{~s}$ of arc $(34.0 \%)$. In addition, $14(1.0 \%)$ children had 'unable' stereoacuity.

The mean stereoacuity was $53.2 \pm 1.7 \mathrm{~s}$ of arc in the first-born group, $56.9 \pm 1.9 \mathrm{~s}$ of arc in the second-born group and $60.9 \pm 1.5 \mathrm{~s}$ of arc in the third-born group. The percentage of children with stereoacuity of $40 \mathrm{~s}$ of arc decreased from $56.3 \%$ in the first-born group to $30.0 \%$ in the third-born group. A significant difference in stereoacuity among birth order groups was found $(\mathrm{p}=0.034)$.

\section{Early life factors associated with stereoacuity in Chinese preschool children}

In univariate analysis, age in months $(\mathrm{p}=0.028)$, maternal age $(p=0.039)$, birth weight $(p=0.003)$, Apgar score at 5 min $(\mathrm{p}=0.030)$ and breast feeding $(\mathrm{p}=0.015)$ were all significantly associated with stereoacuity (table 3 ). Other factors such as gender, gestational age at birth, delivery mode, neonatal oxygen supplementation, birth order and smoking exposure were not significantly correlated
Table 1 Characteristics of early life factors among preschool children in the Nanjing Eye Study $(\mathrm{N}=1342)$

\begin{tabular}{|c|c|c|}
\hline Characteristics & n (\%) & Mean \pm SD \\
\hline \multicolumn{3}{|l|}{ Gender } \\
\hline Male & $721(53.7)$ & \\
\hline Female & $621(46.3)$ & \\
\hline Age in months & & $66.79 \pm 3.38$ \\
\hline Maternal age & & $26.22 \pm 3.86$ \\
\hline \multicolumn{3}{|c|}{ Gestational age at birth (weeks) } \\
\hline$<37$ & $64(4.8)$ & \\
\hline $37-42$ & $1216(90.6)$ & \\
\hline$\geq 42$ & $62(4.6)$ & \\
\hline Birth weight $(\mathrm{kg})$ & & $3.33 \pm 0.52$ \\
\hline \multicolumn{3}{|l|}{ Apgar score at $5 \mathrm{~min}$} \\
\hline $7-10$ & $1305(97.2)$ & \\
\hline$<7$ & $37(2.8)$ & \\
\hline \multicolumn{3}{|l|}{ Delivery mode } \\
\hline Vaginal delivery & $756(56.3)$ & \\
\hline Caesarean delivery & $586(43.7)$ & \\
\hline \multicolumn{3}{|c|}{ Neonatal oxygen supplementation } \\
\hline Yes & $76(5.7)$ & \\
\hline No & $1266(94.3)$ & \\
\hline \multicolumn{3}{|l|}{ Birth order } \\
\hline First & $1083(80.7)$ & \\
\hline Second & $239(17.8)$ & \\
\hline Third & $20(1.5)$ & \\
\hline \multicolumn{3}{|l|}{ Smoking exposure } \\
\hline Yes & $172(12.8)$ & \\
\hline No & $1170(87.2)$ & \\
\hline \multicolumn{3}{|l|}{ Breast feeding } \\
\hline Exclusively & $652(48.6)$ & \\
\hline Partially & $561(41.8)$ & \\
\hline None & $129(9.6)$ & \\
\hline
\end{tabular}

with stereoacuity. In multivariate analysis, younger age in months $(\mathrm{p}=0.012)$, lower birth weight $(\mathrm{p}=0.003)$, higher birth order $(\mathrm{p}=0.036)$ and less breast feeding $(\mathrm{p}=0.023)$ were significantly correlated with poorer stereoacuity (table 3). Higher birth order was associated with poorer stereoacuity, with adjusted mean stereoacuity of 53.3, 56.7 and $62.1 \mathrm{~s}$ of arc for the first-born, second-born and thirdborn groups, respectively.

In the univariate analysis of the early life factors associated with subnormal stereoacuity, younger age in months $(\mathrm{p}<0.001)$, older maternal age $(\mathrm{p}=0.035)$, lower birth weight $(\mathrm{p}=0.002)$, higher birth order $(\mathrm{p}=0.043)$ and less breast feeding $(\mathrm{p}=0.007)$ were all correlated with higher risk of subnormal stereoacuity (table 4). In multivariate analysis, young age in months $(\mathrm{OR}=0.94, \mathrm{p}<0.001)$, 
Table 2 Distribution of stereoacuity in preschool children overall and by birth order group

\begin{tabular}{|c|c|c|c|c|}
\hline \multirow[b]{2}{*}{ Stereoacuity (in seconds of arc) } & \multirow[b]{2}{*}{$\begin{array}{l}\text { All }(\mathrm{N}=1342) \\
\mathrm{n}(\%)\end{array}$} & \multicolumn{3}{|l|}{ Birth order } \\
\hline & & $\begin{array}{l}\text { First }(n=1083) \\
n(\%)\end{array}$ & $\begin{array}{l}\text { Second }(n=239) \\
n(\%)\end{array}$ & $\begin{array}{l}\text { Third }(n=20) \\
n(\%)\end{array}$ \\
\hline 40 & $740(55.1)$ & $610(56.3)$ & $124(51.9)$ & $6(30.0)$ \\
\hline 60 & $456(34.0)$ & $364(33.6)$ & $82(34.3)$ & $10(50.0)$ \\
\hline 100 & $100(7.5)$ & $75(6.9)$ & $22(9.2)$ & $3(15.0)$ \\
\hline 200 & $12(0.9)$ & $8(0.7)$ & $3(1.3)$ & $1(5.0)$ \\
\hline 800 & $8(0.6)$ & $4(0.4)$ & $4(1.7)$ & 0 \\
\hline Unable & $14(1.0)$ & $11(1.0)$ & $3(1.3)$ & 0 \\
\hline Mean $\pm \mathrm{SD}^{*}$ & $54.0 \pm 1.7$ & $53.2 \pm 1.7$ & $56.9 \pm 1.9$ & $60.9 \pm 1.5$ \\
\hline Median (first quartile, third quartile) & $40(40,60)$ & $40(40,60)$ & $40(40,60)$ & $60(40,60)$ \\
\hline
\end{tabular}

*The stereoacuity values were first transformed to logarithmic values to calculate the mean and SD, then transformed back to arc second values.

low birth weight $(\mathrm{OR}=0.71, \mathrm{p}=0.001)$, high birth order $(\mathrm{OR}=1.22, \mathrm{p}=0.17$ for the second-born group; $\mathrm{OR}=3.02$, $\mathrm{p}=0.027$ for the third-born group) and never breast feeding ( $\mathrm{OR}=1.79, \mathrm{p}=0.004$ ) were identified as independent indicators of subnormal stereoacuity.

\section{DISCUSSION}

In this study, we found that lower birth order was linked to better stereoacuity and lower risk of subnormal stereoacuity after adjusting for a wide range of factors in Chinese preschool children.

Although the difference among the three groups was small, combining with also a small number of laterborns, as well as the small SD (1.5 1.9), it might indicate those later-borns would have more difficulties in real situation than the first-borns. General findings from individuals with abnormal binocular function, such as poor stereoacuity, expressed impairment in motor control-movement speed, accuracy or both. Each of the activity was correlated with loss of stereoacuity, but not with severity of amblyopia. Impairments were especially

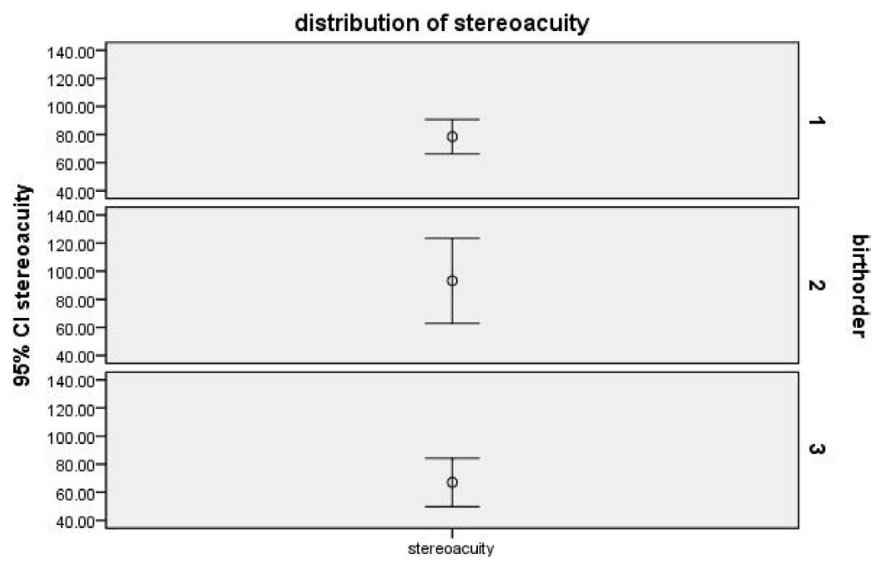

Figure 1 Distribution of stereoacuity. 1: first birth order group; 2: second birth order group; 3: third birth order group. Stereoacuity in seconds of arc. marked when the task was time-limited or novel. We suggest paying more attention to later-borns with poor stereoacuity and following up their stereoacuity and stereomotion development.

To the best of our knowledge, this is one of the few population-based studies investigating the association between birth order and stereoacuity in preschool children. Our study found that later-borns had poorer stereoacuity and greater risk of subnormal stereoacuity than first-borns.

From neurological development perspective, there are several reasons for our findings. First, some studies found that higher birth order was associated with higher risk of neurodevelopmental disorders, such as schizophrenia. ${ }^{5}$ Second, birth order has been reported to be related to grey matter volume. Comparing with first-born twins, second-born twins had smaller grey matter volume, indicating aberrant early brain development in the second-born twins, which could be also generalised to the singleton population. ${ }^{15}$ Third, first-borns tend to overtake later-borns in intellectual performance by tutoring younger siblings. ${ }^{2}$ Although it was reported later-borns could benefit from interacting with older siblings, ${ }^{16} 17$ this benefit might be cast into the shade compared with firstborns tutoring younger siblings. Fourth, the maternal immune hypothesis has suggested the probability of maternal immune attack on the fetal brain increasing with increased parity. ${ }^{18}{ }^{19}$ Similarly, Rostila and Saarela ${ }^{20}$ thought increased maternal antibody levels with high birth order might have a negative influence on fetal brain development. Finally, some reports found that laterborns with multiple siblings had a greater risk of exposure to common childhood pathogenic micro-organisms, including bacteria and viruses, at the time of birth than the first-borns, ${ }^{21-23}$ which might also be a threat to brain development. Nevertheless, there are no data available demonstrating possible factors in this study, making it difficult to determine the underlying mechanism of poor stereoacuity in later-borns. 
Table 3 Univariate and multivariate linear regression analyses on the associations between early life factors and stereoacuity

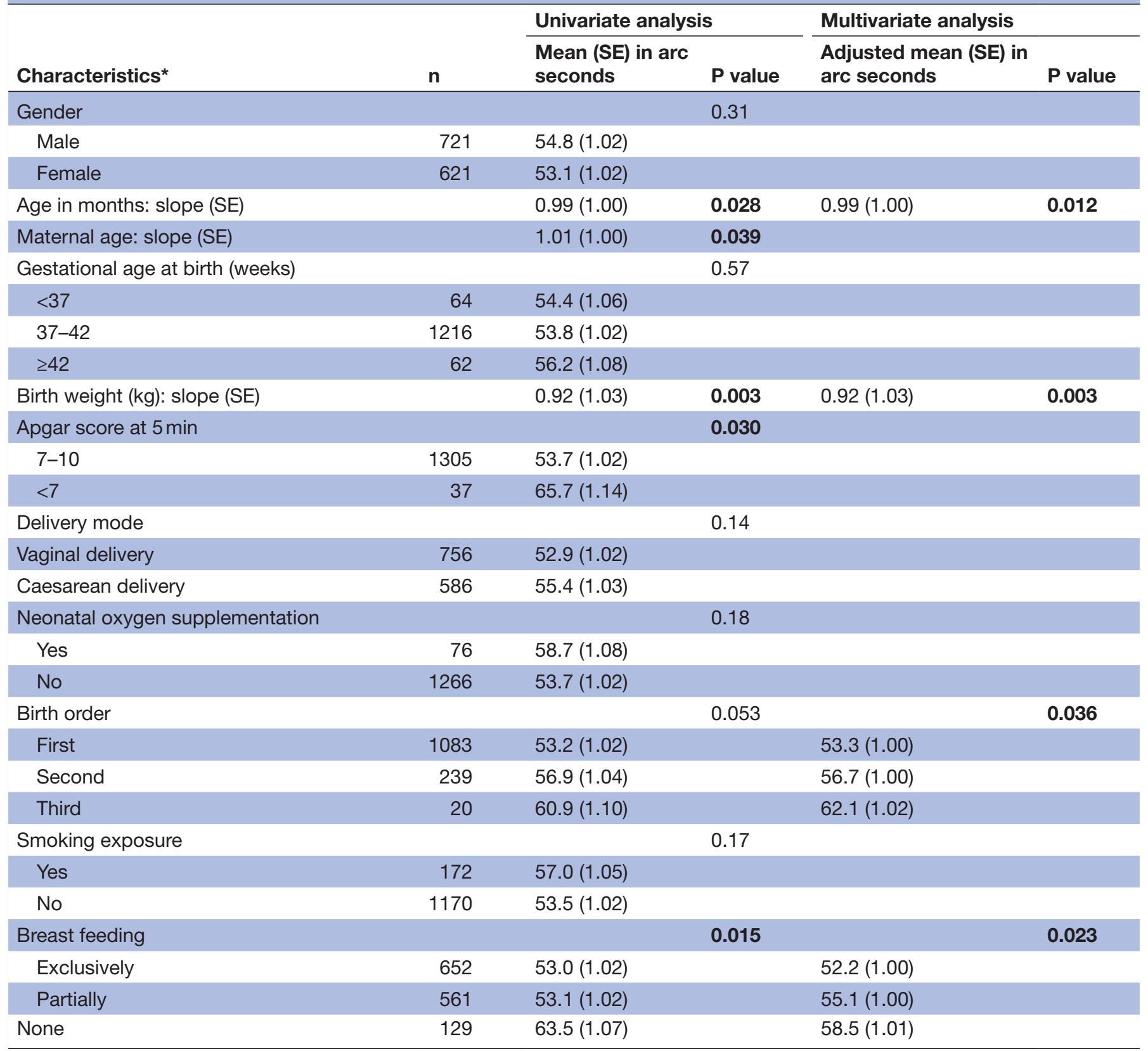

Bold type indicates statistical significance $(p<0.05)$.

${ }^{*}$ Factor was not included in the final multivariate model because it was not statistically significant.

$\mathrm{SE}$, standard error.

In terms of potential psychosocial explanations for the association between stereoacuity and birth order, a dilution of resources for later-borns should be mentioned, ${ }^{24}$ which showed parents' attention and material resources were limited. For one thing, children of higher birth order receive less parental attention and supervision partly due to limited time. First-borns might be the only baby when they were born, while later-borns were not. Limited parental attention and supervision also meant less attention paid to later-borns' health and safety, including psychological health and signs of psychiatric deviations, which are a threat to neurodevelopment. For another, the more children raised in one family, the less resource each offspring receives .

As we all know, stereoacuity is the highest form of sensory fusion and reflects neurodevelopment in children. $^{7825}$ Thus the poor stereoacuity among later-borns might illustrate compromised global development, including gross and fine motor, ${ }^{26}$ language, ${ }^{27}{ }^{28}$ sensory $^{29}$ and socialisation. ${ }^{30}$ We attempted to find the possible causes of poor stereoacuity among later-borns from the paediatric ophthalmology perspective, but no significant correlation was found between birth order and myopia, hyperopia, astigmatism, anisometropia, strabismus or 
Table 4 Univariate and multivariate analyses on the associations between early life factors and subnormal stereoacuity ${ }^{*}$

\begin{tabular}{|c|c|c|c|c|c|c|c|c|}
\hline \multirow[b]{2}{*}{ Characteristics $†$} & \multirow[b]{2}{*}{$\mathbf{n}$} & \multirow{2}{*}{$\begin{array}{l}\text { Subnormal } \\
\text { stereopsis* } \\
\mathrm{n}(\%)\end{array}$} & \multicolumn{3}{|c|}{ Univariate analysis } & \multicolumn{3}{|c|}{ Multivariate analysis } \\
\hline & & & OR & $95 \% \mathrm{Cl}$ & $P$ value & OR & $95 \% \mathrm{Cl}$ & $P$ value \\
\hline \multicolumn{9}{|l|}{ Gender } \\
\hline Male & 721 & $337(46.7)$ & 1.00 & & & & & \\
\hline Female & 621 & $265(42.7)$ & 0.85 & 0.68 to 1.05 & 0.14 & & & \\
\hline Age in months & & & 0.94 & 0.91 to 0.97 & $<0.001$ & 0.94 & 0.91 to 0.97 & $<0.001$ \\
\hline Maternal age & & & 1.03 & 1.00 to 1.06 & 0.035 & & & \\
\hline Gestational age at birth (weeks) & & & & & 0.37 & & & \\
\hline$<37$ & 64 & $34(53.1)$ & 1.42 & 0.86 to 2.36 & 0.17 & & & \\
\hline $37-42$ & 1216 & $539(44.3)$ & 1.00 & & & & & \\
\hline$\geq 42$ & 62 & $29(46.8)$ & 1.10 & 0.66 to 1.84 & 0.71 & & & \\
\hline Birth weight & & & 0.72 & 0.59 to 0.89 & 0.002 & 0.71 & 0.57 to 0.88 & 0.001 \\
\hline \multicolumn{9}{|l|}{ Apgar score at $5 \mathrm{~min}$} \\
\hline $7-10$ & 1305 & $581(44.5)$ & 1.00 & & & & & \\
\hline$<7$ & 37 & $21(56.8)$ & 1.64 & 0.85 to 3.16 & 0.14 & & & \\
\hline \multicolumn{9}{|l|}{ Delivery mode } \\
\hline Vaginal delivery & 756 & $343(45.4)$ & 1.00 & & & & & \\
\hline Caesarean delivery & 586 & $259(44.2)$ & 0.95 & 0.77 to 1.19 & 0.67 & & & \\
\hline \multicolumn{9}{|l|}{$\begin{array}{l}\text { Neonatal oxygen } \\
\text { supplementation }\end{array}$} \\
\hline Yes & 76 & $40(52.6)$ & 1.39 & 0.88 to 2.21 & 0.16 & & & \\
\hline No & 1266 & $562(44.4)$ & 1.00 & & & & & \\
\hline Birth order & & & & & 0.043 & & & 0.040 \\
\hline First & 1083 & $473(43.7)$ & 1.00 & & & 1.00 & & \\
\hline Second & 239 & $115(48.1)$ & 1.20 & 0.90 to 1.58 & 0.21 & 1.22 & 0.92 to 1.63 & 0.17 \\
\hline Third & 20 & $14(70.0)$ & 3.01 & 1.15 to 7.89 & 0.025 & 3.02 & 1.13 to 8.04 & 0.027 \\
\hline \multicolumn{9}{|l|}{ Smoking exposure } \\
\hline Yes & 172 & $88(51.2)$ & 1.34 & 0.97 to 1.84 & 0.08 & & & \\
\hline No & 1170 & $514(43.9)$ & 1.00 & & & & & \\
\hline Breast feeding & & & & & 0.007 & & & 0.009 \\
\hline Exclusively & 652 & $283(43.4)$ & 1.00 & & & 1.00 & & \\
\hline Partially & 561 & $244(43.5)$ & 1.00 & 0.80 to 1.26 & 0.97 & 0.99 & 0.79 to 1.25 & 0.96 \\
\hline None & 129 & $75(58.1)$ & 1.81 & 1.24 to 2.66 & 0.002 & 1.79 & 1.21 to 2.64 & 0.004 \\
\hline
\end{tabular}

Bold type indicates statistical significance $(p<0.05)$.

*Subnormal stereoacuity was defined as stereoacuity worse than $40 \mathrm{~s}$ of arc (stereoacuity value $>40 \mathrm{~s}$ of arc).

†Factor was not included in the final multivariate model because it was not statistically significant.

amblyopia. We supposed poor stereoacuity is a marker of compromised global development. It might be necessary to assess later-borns in the long term with regard to both neurological development and health development.

Besides high birth order, low birth weight and never breast feeding were also correlated with poor stereoacuity, suggesting the importance of early intervention during pregnancy and the perinatal period, especially for later-borns. Thus, to improve paediatric healthcare, it is also important to strengthen healthcare during pregnancy and childbirth.
Our study had several limitations. First, 578 children who did not finish the examination or questionnaire were excluded from the analyses, which might bias our results. Second, the stereoacuity measurement of some children might not be accurate enough due to poor compliance. Third, only age in months, gender and early life factors were included in the multivariate analysis. It is possible that other unknown or unexplored factors might also contribute to poor stereoacuity.

In conclusion, later-borns had poorer stereoacuity than first-borns. Given the increasing number of later-borns 
following the two-child policy in China, there would be an alarming increase in the burden on healthcare for children. To better manage the forthcoming challenge, more attention should be paid to later-borns.

Acknowledgements We thank the children, their parents or legal guardians, and all the members of the Maternal and Child Healthcare Hospital of Yuhuatai District, Nanjing, China, for their helpful advice and support.

Contributors $\mathrm{XHZ}, \mathrm{RL}, \mathrm{HT}, \mathrm{XYZ}, \mathrm{YW}, \mathrm{QH}, \mathrm{DH}, \mathrm{HZ}$ and $\mathrm{HL}$ : design of the work. $\mathrm{XHZ}$, $\mathrm{RL}, \mathrm{HT}, \mathrm{XYZ}, \mathrm{YW}, \mathrm{QH}, \mathrm{DH}, \mathrm{HZ}, \mathrm{XJZ}$ and $\mathrm{HL}$ : acquisition of data. RL, DH, HZ, XJZ and SH: analysis of data. SH, RL, HT, XYZ, YW, QH, XJZ and DH: drafting of the manuscript. $\mathrm{SH}, \mathrm{XHZ}, \mathrm{HZ}, \mathrm{XJZ}$ and $\mathrm{HL}$ : revising it critically for important intellectual content. All authors approved the version to be published.

Funding This work is supported by the National Natural Science Foundation of China (grant no 81673198 and 81803258); the Natural Science Foundation of Jiangsu Province (grant no BK20161595); Jiangsu Province's Key Provincial Talent Program (grant no QNRC2016563); and Postgraduate Research and Practice Innovation Program of Jiangsu Province (grant no SJCX18_0432).

Competing interests None declared.

Patient and public involvement Patients and/or the public were not involved in the design, or conduct, or reporting, or dissemination plans of this research.

Patient consent for publication Not required.

Ethics approval This study was approved by the Ethics Committee of The First Affiliated Hospital of Nanjing Medical University and followed the tenets of the Declaration of Helsinki.

Provenance and peer review Not commissioned; externally peer reviewed.

Data availability statement No data are available.

Open access This is an open access article distributed in accordance with the Creative Commons Attribution Non Commercial (CC BY-NC 4.0) license, which permits others to distribute, remix, adapt, build upon this work non-commercially, and license their derivative works on different terms, provided the original work is properly cited, appropriate credit is given, any changes made indicated, and the use is non-commercial. See: http://creativecommons.org/licenses/by-nc/4.0/.

ORCID iD

Hu Liu http://orcid.org/0000-0002-3952-4165

\section{REFERENCES}

1 Cheng PJ, Duan T. China's new two-child policy: maternity care in the new multiparous era. BJOG 2016;123:7-9.

2 Kristensen P, Bjerkedal T. Explaining the relation between birth order and intelligence. Science 2007;316:1717.

3 Vanderlaan DP, Blanchard R, Zucker KJ, et al. Birth order and ANDROPHILIC male-to-female transsexualism in Brazil. J Biosoc Sci 2017;49:527-35.

4 Damian RI, Roberts BW. Settling the debate on birth order and personality. Proc Natl Acad Sci U S A 2015;112:14119-20.

5 Gaughran F, Blizard R, Mohan R, et al. Birth order and the severity of illness in schizophrenia. Psychiatry Res 2007;150:205-10.

6 Schug RA, Yang Y, Raine A, et al. Structural and psychosocial correlates of birth order anomalies in schizophrenia and homicide. $J$ Nerv Ment Dis 2010;198:870-5.

7 Ponsonby A-L, Smith K, Williamson E, et al. Poor stereoacuity among children with poor literacy: prevalence and associated factors. Optom Vis Sci 2013;90:75-83.
8 Richardson SR, Wright CM, Hrisos S, et al. Stereoacuity in unilateral visual impairment detected at preschool screening: outcomes from a randomized controlled trial. Invest Ophthalmol Vis Sci 2005;46:150-4.

9 Huang D, Chen X, Zhu H, et al. Prevalence of amblyopia and its association with refraction in Chinese preschool children aged 36-48 months. Br J Ophthalmol 2018;102:767-71.

10 Zhu H, Huang D, Sun Q, et al. Normative visual acuity in Chinese preschoolers aged 36 to $<48$ months as measured with the linear HOTV chart: the Yuhuatai Pediatric Eye Disease Study. BMJ Open 2017;7:e014866.

11 Huang $D$, Chen $X$, Zhang $X$, et al. Pediatric vision screening using the plusoptiX A12C photoscreener in Chinese preschool children aged 3 to 4 years. Sci Rep 2017;7:2041.

12 Zhang X, Wang Y, Huang D, et al. Prevalence of reduced visual acuity among preschool children in eastern China and comparison at a 5year interval. Clin Exp Ophthalmol 2018;46:994-1001.

13 Multi-Ethnic Pediatric Eye Disease Study (MEPEDS) Group. Prevalence and causes of visual impairment in African-American and Hispanic preschool children: the multi-ethnic pediatric eye disease study. Ophthalmology 2009;116:1990-2000.

14 Han S, Zhang X, Zhao X, et al. Stereoacuity and related factors in healthy preschool children: the Nanjing eye study. Ophthalmic Epidemiol 2019;26:336-44.

15 Hulshoff Pol HE, Posthuma D, Baaré WFC, et al. Twin-singleton differences in brain structure using structural equation modelling. Brain 2002;125:384-90.

16 McHale SM, Updegraff KA, Helms-Erikson $\mathrm{H}$, et al. Sibling influences on gender development in middle childhood and early adolescence: a longitudinal study. Dev Psychol 2001;37:115-25.

17 Hanna E, Meltzoff AN. Peer imitation by toddlers in laboratory, home, and day-care contexts: implications for social learning and memory. Dev Psychol 1993;29:701-10.

18 Blanchard R. Fraternal birth order and the maternal immune hypothesis of male homosexuality. Horm Behav 2001;40:105-14.

19 Blanchard R. Quantitative and theoretical analyses of the relation between older brothers and homosexuality in men. $J$ Theor Biol 2004;230:173-87.

20 Rostila M, Saarela J. Invited commentary: birth order and suicide in a broader context. Am J Epidemiol 2013;177:645-8.

21 Hsieh CC, Tzonou A, Zavitsanos X, et al. Age at first establishment of chronic hepatitis $B$ virus infection and hepatocellular carcinoma risk. A birth order study. Am J Epidemiol 1992;136:1115-21.

22 Goldacre MJ. Space-time and family characteristics of meningococcal disease and Haemophilus meningitis. Int $\mathrm{J}$ Epidemiol 1977;6:101-5.

23 Kuper $\mathrm{H}$, Hsieh C, Stuver SO, et al. Birth order, as a proxy for age at infection, in the etiology of hepatocellular carcinoma. Epidemiology 2000;11:680-3.

24 Blake J. Number of siblings and educational attainment. Science 1989;245:32-6.

25 Bax M, Whitmore K. Neurodevelopmental screening in the schoolentrant medical examination. Lancet 1973;2:368-70.

26 St John T, Estes AM, Dager SR, et al. Emerging executive functioning and motor development in infants at high and low risk for autism spectrum disorder. Front Psychol 2016;7:1016.

27 Berken JA, Gracco VL, Klein D. Early bilingualism, language attainment, and brain development. Neuropsychologia 2017;98:220-7.

28 Sharda M, Foster NEV, Tryfon A, et al. Language ability predicts cortical structure and covariance in boys with autism spectrum disorder. Cereb Cortex 2017;27:1849-62.

29 Tudela-Torras M, Abad-Mas L, Tudela-Torras E. [Sensory integration: benefits and effectiveness of therapeutic management in sensory processing disorders]. Rev Neurol 2017;64:S73-7.

30 Medina Alva MdeIP, Kahn IC, Muñoz Huerta P, et al. [Child neurodevelopment: normal characteristics and warning signs in children under five years]. Rev Peru Med Exp Salud Publica 2015;32:565-73. 